Journal of the Scholarship of Teaching and Learning, Vol. 21, No. 1, April 2021, pp. 72-83.

doi: 10.14434/josotl.v21i1.30361

\title{
Undergraduate Researchers: Mentees and Mentors
}

\author{
Jenni L. Redifer \\ Western Kentucky University \\ jenni.redifer@,wku.edu \\ Derick Strode \\ Western Kentucky University \\ Cathleen Webb \\ Western Kentucky University
}

\begin{abstract}
This article describes the tiered mentoring approach to undergraduate research at a regional comprehensive university. In addition to mentorship of undergraduate student researchers by faculty and graduate students, tiered mentoring includes high school student researchers. The high-impact practice of student research is particularly impactful at this institution, where $40 \%$ of first-year students are first-generation college students, and the campus houses a residential science, technology, engineering, and mathematics high school. The wide variety of opportunities for student research involvement, including opportunities for students to serve in both mentee and mentor roles, has contributed to tiered mentorship becoming a prominent component of our university culture. Strategies for beginning and expanding the involvement of high school students as researchers in postsecondary settings are discussed.
\end{abstract}

Keywords: student research, peer mentoring, high school students, tiered mentoring

Undergraduate research is categorized as a high-impact practice because of its effect on academic performance (Bhattacharyya, Chan, \& Waraczynski, 2018; Fechheimer, Webber, \& Kleiber, 2011; Kuh, 2008), scientific skills, pursuit of scientific careers (Lopatto, 2010), and retention of students who are female or members of minority racial or ethnic groups (Nagda, Gregerman, Lerner, Von Hippel, \& Jonides, 1998). Mentoring is a critical component of many research programs for undergraduates, and the mentoring aspect of student research appears to be particularly beneficial for science, technology, engineering, and mathematics (STEM) students who are members of underrepresented groups (MacPhee, Farro, \& Canetto, 2013).

This article examines the benefits of mentored research to student researchers, their faculty mentors, and to the universities and communities where the work takes place. We discuss the benefits of undergraduates not only receiving mentorship in research, but also serving as mentors to less experienced researchers. We refer to this as a tiered-mentorship approach and examine the learning that takes place as more experienced student researchers communicate and guide their less experienced peers. We profile the tiered-mentorship approach at a regional comprehensive university, including an intensive focus on how high school students from an on-campus specialized, residential high school academy at the university are involved in mentored research. Although some components of our institution's method of involving high school students in research are specific to the residential academy structure, others are more widely applicable. Approaches to involving high school students in mentored research used by other universities and research organizations are also discussed. Finally, we outline strategies for establishing a culture of providing research mentorship to high school students in a postsecondary environment. 


\section{Mentored Research: Increasing the Reach of a High-Impact Practice}

In addition to the numerous deep-learning opportunities for high school students, mentored research can be hugely beneficial to participating faculty and undergraduate researchers. In our experience, high school students who seek out additional research opportunities are highly motivated and can often be described as "self-starters." However, barriers to access may discourage some high school students who would otherwise be inclined to seek out research opportunities at a college or university. Purposeful outreach from postsecondary institutions to secondary schools to engage high school students early is one way to begin removing barriers. One widely utilized practice is dual-credit relationships between high schools and local colleges. These programs bridge high school to university classroom learning experiences, expand high schools' curricular offerings, and ready students for the rigor of college, providing appropriately challenging offerings to interested students. Scaffolding from this common model of dual-credit collaborations, we encourage high schools and universities to examine their local communities anew to identify partnerships to engage high school students in mentored research. High schools can work to facilitate this process, as some magnet schools have done by recruiting research mentors and matching them up with students (Wheeler High School, 2020). Similarly, some universities have created pipeline programs to involve high school students in original, mentored research. Alternatively, welcoming faculty mentors may even invite local high school students into their research groups independently, finding that it is a student's curiosity, not their age or grade level, that leads to success in research (Murray, Obare, \& Hageman, 2016; Roberts, Breedlove, \& Strode, 2016).

By involving area high school students in mentored research projects, universities provide an outlet for higher level learning that few high schools have the resources or ability to provide. Barriers to conducting mentored research in secondary schools include limited budgets, expectations to prepare students for performance on standardized metrics, lack of access to advanced equipment and instrumentation, and little time in the face of other demands (Murray et al., 2016). For high school students, mentored research is a way to harness academic energy into meaningful contributions to real problems, and to enhance the scope of academic experiences. Those who offer student research opportunities provide a mechanism to accelerate learning in ways high schools cannot do alone. Murray et al. (2016, p. 3) called for research access for students to be "early, often, and universal," suggesting that if all students could conduct original research, early results would include a more scientifically literate population overall, more students pursuing STEM, a homegrown, innovative culture, and greater diversity in the STEM workforce.

Professional organizations can also play a role in facilitating high school student involvement in research, as well as in encouraging faculty to invite high school student researchers into their research groups. The American Chemical Society's Project SEED (Summer Experiences for the Economically Disadvantaged) provides funding for high school students to conduct research on campus with university faculty during the summer. The American Psychological Association (APA; 2020) maintains a list of research mentors by state, including those willing to mentor high school students. The APA (2016) also publishes a freely available manual for conducting psychological research for science fairs. Both APA resources provide avenues for faculty to reach out to high school students to provide mentoring, access to laboratory equipment, and other support to facilitate independent or guided research.

\section{Other Routes to Mentored Research for High School Students}

Summer research internships offer another avenue for high school student research involvement. Examples include the Research Science Institute and the Summer Science Program. Students from

Journal of the Scholarship of Teaching and Learning, Vol. 21, No. 1, April 2021. josotl.indiana.edu 
both programs conduct research at universities with faculty mentors, and these programs provide the opportunity to engage in full-time research for several months. The Research Science Institute is hosted by the Massachusetts Institute of Technology (MIT). Participants are placed under mentorship from faculty at MIT, other Boston area universities, and corporate and government-sponsored research labs. Summer Science Programs take place at New Mexico Tech, University of Colorado Boulder, Purdue University, and Indiana University. Additionally, the National Institutes of Health's Summer Internship Program welcomes high school and undergraduate applicants, placing students under mentorship from NIH professionals. Like traditional academic-year experiences, summer research programs give high school students the opportunity to explore research, but in a more immersive way than many undergraduate students ever experience.

Murray et al. (2016) compiled an extensive list of competitions, fairs, and internship programs specific to high school researchers, as well as a collection of journals for early-career researchers. Many discipline-specific conferences and meetings have a student poster session that is also open to high school students. In addition to programs designed specifically for high-school-aged researchers, mentors can involve younger researchers in working toward the same outcomes that undergraduates in the lab may be working toward.

\section{Benefits of Mentored Research for Students}

High school students who seek research opportunities at local universities are often hungry for challenge and seek a supportive environment to grow their own skills quickly. This drive can help them become productive, task-focused, dedicated researchers. High school students who conduct mentored research often achieve the same outcomes as their undergraduate peers, including presenting at discipline-specific meetings and conferences or coauthorship of manuscripts. In a research mentoring program for high school sophomores, notable outcomes included studentauthored scientific publications and significantly higher science knowledge and scores on measures of 21st-century skills among participants, compared to a control group (Puslednik \& Brennan, 2020). Faculty researchers who mentor high school students form teaching relationships with teams of students interested in similar problems and reap the reward of nurturing the next generation of motivated researchers. Likewise, students who take on research projects are motivated by faculty who take an interest in and encourage them to think in new and more complex ways, resulting in students who become "hooked on learning" (Atkinson, Hugo, Lundgren, Shapiro, \& Thomas, 2007) and who work harder as a result.

Another advantage of bringing younger students into a research group is the ability to create a tiered, team mentorship model. The tiered approach holds advantages for everyone involved. In fields where the benefits of mentorship are well established, a tiered approach can increase the likelihood that students receive mentoring (Kman, Bernard, Khandelwal, Nagel, \& Martin, 2013). By empowering more experienced student researchers to train, teach, or co-mentor newer team members to operate equipment, follow research protocols, and analyze data, faculty time can be redirected toward activities that benefit the entire research group but are not as easily delegated (e.g., planning future research projects). At the same time, the benefits of learning through teaching trickle down to other members, who may later become research mentors themselves. Serving as a peer mentor in a college setting provides numerous advantages, both academically and socially, for the mentor (Kiyama \& Luca, 2014). Tiered mentorship leads to research groups comprising students with varying levels of expertise and evolving degrees of leadership. Thus, students experience rich teamwork situations that go far beyond the typical class project. Results from the Summer Undergraduate Research Experience survey indicate that the more experienced members of groups who provide peer mentorship to newer

Journal of the Scholarship of Teaching and Learning, Vol. 21, No. 1, April 2021. josotl.indiana.edu 
members enjoy the teaching role and see self-benefits, including a growth in self-confidence, increase in their own motivation, and improved communication skills (Lopatto, 2010).

For the student researcher, benefits are both professional and personal (Lopatto, 2010). Mentored research is a means to explore career options. As students enter college and declare majors, they may narrow their choices to options with which they are already somewhat familiar. Taking classes within the major helps students understand if the choice is a good fit for them individually. However, this is a slow, trial-and-error process leading to many students changing majors as they learn more about their own fit within a discipline and resultant career options. Involvement in research accelerates this self-exploration, helping students quickly understand how a professional within that discipline approaches and solves problems. Participating in research is also a confirming and clarifying experience, with many students "fine tuning" their career plan as a result of what they learned about themselves during their experience (Lopatto, 2010). High school student involvement in mentored research can serve as an even earlier strategy to help students find clarity when choosing a major and assessing career options (Roberts, 2013). Early involvement in research provides an early confidence boost, strengthens teamwork skills for the young participant (Bhattacharyya et al., 2018), and results in a deeper understanding of science (Murray et al., 2016). As Atkinson et al. (2007) noted, when highly motivated students interact with peers and teachers who care about the same problems as they do, they find new motivation and self-validation, some realizing for the first time that it is good to be smart.

For high school students, mentored research can lead to a plethora of opportunities for additional experience and recognition. The Regeneron Science Talent Search is the oldest and most prestigious high school research competition, accepting research reports from high school researchers around the nation. Prizes are awarded, including the $\$ 250,000$ top prize. The Regeneron International Science and Engineering Fair brings together 1,800 top students from around the world each year to discuss or demonstrate their work, resulting in $\$ 5$ million in scholarship awards. Other competitions are open to students in disciplines outside of STEM, such as the Davidson Fellowship, which targets students 18 and under who have completed a major body of original work. A substantial number of the students who have reached these impressive stages conducted their work at a local university with mentorship from university faculty.

\section{Benefits of Peer Mentoring for Mentors and Faculty Supervisors}

Interaction with peers during the research process is common among undergraduate researchers and is viewed favorably by both mentors and mentees (Hayes, 2018; Lopatto, 2010). Student researchers who have served as mentors to other students have described their experience as a boon to their communication skills and motivation to conduct research (Lopatto, 2010). The interactive process of peer mentoring illustrates the benefits of learning as a social activity and exemplifies the idea of teaching as learning (Lave, 1996). Serving as a mentor also enriches the student researcher's grasp of the content: The process of explaining material to someone else and answering questions about the material, as in the case of peer tutoring, strengthens tutors' understanding (Evans \& Cuffe, 2009) and encourages them to investigate the answers to questions they are unable to answer (Galbraith \& Winterbottom, 2011). These benefits increase when the to-be-learned material is more complex (Duran, 2017), a likely scenario for research mentoring. Serving as a peer mentor can "professionalize" the research experience for undergraduate researchers, giving them an additional sense of responsibility above and beyond their regular lab duties. Undergraduate research mentors may feel a sense of ownership of the area in which they are mentoring other students, which can increase their engagement (National Survey of Student Engagement, 2005), sense of purpose, and research selfefficacy (Berkes \& Hogrebe, 2007).

Journal of the Scholarship of Teaching and Learning, Vol. 21, No. 1, April 2021. josotl.indiana.edu 
Faculty who encourage peer mentoring in their research groups may also benefit from this process: When student researchers are allowed to take on leadership roles, they can then model the mentoring process for mentees who may eventually serve as mentors themselves. Using a mentorship structure can increase faculty members' research productivity and output (Morrison-Beedy, Aronowitz, Dyne, \& Mkandawire, 2001). For faculty who invite high school student researchers into their research groups, potential benefits include working with highly motivated individuals, resultant lab group productivity, more robust progress on initiatives, and increased scholarly output including presentations, publications, and external funding efforts, as well as the opportunity to mentor motivated individuals who challenge the mentors themselves. Students who are ready to serve as mentors are typically also ready to contribute more to the research process and may feel greater responsibility for project outcomes than students who see their roles as less responsible. In a practical sense, allowing trustworthy student mentors to serve as leaders may help a faculty member's research group or laboratory function more efficiently, without constant oversight of every task from the faculty member. For example, Texas A\&M University's LAUNCH (learning communities, academic excellence, undergraduate research, national fellowships, capstones, and honors) program provides broad access to research opportunities across many different disciplines. More experienced student researchers serve as team leaders who not only direct projects but also review applicants and select new student researchers to join the team. Thus, a tiered-mentoring approach is built into the LAUNCH model, owing to its incorporation of student-led projects, potentially reducing the workload of faculty who serve the initiative. The student-led structure may also help research seem more welcoming to students who are intimidated by the prospect of contacting an unknown faculty member directly, thereby increasing the size of faculty members' applicant pools.

\section{Benefits to Universities and Local Communities}

Universities and local communities benefit from involving high school students in the research process. Precollege research experience can serve as a recruiting mechanism for universities. Early involvement with a research mentor and team of "near peers" can be a deeply rewarding learning experience, helping a high school student imagine the next 4 years at the same institution. Mentored research of high school students can provide long-term benefits to both the student and faculty member if the student elects to complete their postsecondary studies at the same school.

Involving students from the local community in research offers a path to cultural and community insight that faculty often lack, given that many faculty relocate to accept academic positions. Even the undergraduate population does not comprise "locals" in the same sense as high schools. Adding high school students to a research team could be of particular benefit to explorations of community problems that require an understanding of cultural significance, group dynamics, or information that is not well known outside the local community.

\section{Tiered Mentoring: An Approach to Involving High School Students in Research}

Tiered mentoring is utilized in a variety of fields for numerous purposes, including improving retention of community college students (Jaswal \& Jaswal, 2008) and increasing professional development more broadly (Yale University, 2020). Tiered mentoring is an effective approach to introducing students to scientific research (Hayes, 2018). Traditionally, tiered mentoring occurs when a faculty supervisor mentors a graduate student who in turn serves as a mentor to an undergraduate student. For example, in a large psychology research group, faculty might mentor several graduate students who are each responsible for a subgroup working on a portion of the faculty member's larger project. Subgroups could consist of advanced and less-experienced undergraduates who work together

Journal of the Scholarship of Teaching and Learning, Vol. 21, No. 1, April 2021.

josotl.indiana.edu 
to complete tasks such as literature reviews, investigating data collection techniques, and pilot testing study materials. The graduate students would supervise these activities, seeking input from the faculty mentor as needed. Meanwhile, the graduate students would receive mentoring from the faculty mentor. In a biology lab, advanced undergraduates might train less-experienced undergraduates on field data collection protocols, while graduate students train the advanced undergraduates on data analysis techniques and the faculty supervisor mentors graduate students through the manuscript writing and submission process, in addition to providing feedback and guidance on the mentoring provided by the graduate students. Regardless of the discipline, tiered mentoring often involves a faculty member providing "big picture" guidance, with a graduate student responsible for day-to-day supervision of undergraduates, and advanced undergraduates serving as trainers in basic techniques to less advanced undergraduates.

At our regional comprehensive university, undergraduate research is an essential component of faculty scholarship. Approximately $40 \%$ of our first-year students are first-generation college students. Undergraduates are encouraged to join research groups early in their academic careers so that they can learn the skills to design their own studies. By encouraging early student involvement in research through a variety of structures such as course credit for mentored research, combined bachelor's/master's degree programs that have expanded to more than 20 programs in our institution over the past decade, an annual student research conference, and internal undergraduate research grants, we maximize opportunities for advanced scholarship for a broad range of students. As a result, students may start conducting research as first-year students and continue through their senior year, giving them more experience than newer graduate students in the same lab, in some cases. This structure prepares our undergraduate researchers for a wide variety of research roles, including serving as principal investigators of student-led research projects and as mentors to other student researchers. Similar structures can be found across the United States at many types of colleges and universities, ranging from small liberal arts colleges to large research-intensive public universities.

Tiered mentoring can also be applied in research settings that include high school student researchers. High school students may begin their research careers by shadowing undergraduate researchers and enrolling in a lower division independent research course. After receiving training from more advanced student researchers, high school students may move on to collecting data and assisting with research design. Less advanced students need more mentoring. Consequently, the structure of our tiered mentoring approach builds in frequent interaction between new lab members and more experienced researchers. The "tiers" do not insulate faculty members from undergraduates but rather provide the opportunity for mentoring at multiple levels. When high school students join research labs, they receive an even more individualized mentoring experience, benefitting from the guidance of newer undergraduates, advanced undergraduates, graduate students, and faculty.

\section{Strategies to Provide High School Students with Research Mentorship}

Universities or faculty mentors serious about involving high school students in opportunities to conduct mentored research have many models to consider. Options range from individual faculty members allowing high school students to join their research groups to institution-wide partnerships organized with local school districts. Universities with ambitious goals to include high school students might consider partial-day programs arranged with local school districts or target high schools. As in a dual-credit arrangement, upper level high school students could leave the high school for part of the school day to engage in mentored research projects with university faculty. Such an arrangement could result in credit for a university course. Parental and school district support for these programs may increase if they view research participation as a pipeline to expected outcomes such as conference

Journal of the Scholarship of Teaching and Learning, Vol. 21, No. 1, April 2021. josotl.indiana.edu 
presentations, entry to STEM competitions, or facilitation of an application to a prestigious summer research program or scholarship opportunity.

Specialized high schools often have instructional periods dedicated to student engagement in activities such as mentored research. One example is the Illinois Mathematics and Science Academy. Through its Student Inquiry and Research program, students who opt in for research participate with various partners in the greater Chicago area each Wednesday — called Inquiry Days — including at host universities such as the University of Chicago and Northwestern University. At the Clark High School in Cincinnati-the nation's oldest Montessori school-the curricular instruction stops for 2 weeks twice per year for intersession studies while students participate in some form of experiential learning. Such creative arrangements could be reimagined for universities to outreach to local districts or target schools to invite high school students to participate in mentored research projects.

\section{Tiered Mentorship of High School Student Members of the University Community}

One unique aspect of our institution is a statewide, specialized STEM high school located on its campus. The Gatton Academy is a member institution of the National Consortium of Specialized STEM Schools (NCSSS) and fits within the federally defined realm of "specialty-STEM schools" (Every Student Succeeds Act, 2015). There are two types of specialty-STEM schools: self-contained high schools that offer advanced and honors STEM courses, Advanced Placement courses, and dualcredit courses, and high schools that serve as early-college academies, where the curriculum is completely integrated with a university, and students learn from university professors alongside traditional university students (Almarode, Subotnik, \& Lee, 2016; Jones, 2009; Roberts, 2013). The Gatton Academy is an early-college academy, located on the campus of Western Kentucky University and operating as a university academic department. Among the approximately 100 member schools of the NCSSS, almost all have student research programs (Atkinson et al., 2007; Jones, 2009). Schools such as these have been identified as models that provide students with the background to become problem solvers; there are calls to create additional institutions to meet the U.S. demand for qualified STEM professionals (Atkinson et al., 2007; Committee on Prospering in the Global Economy of the 21st Century, 2007).

The Gatton Academy is one of 15 state-supported, residential STEM academies currently in existence, with another slated to open in 2020. High-performing students from across the state who have a demonstrated career interest in STEM are invited to apply for the 2-year program during their high school sophomore year. Through a competitive and holistic admissions process, approximately 100 students are accepted each year, keeping the Gatton Academy's total enrollment near 200 students. During the 2-year program, students complete the requirements for their junior and senior years of high school while integrating academically into early-college life, taking a rigorous college-level STEM curriculum. The students live on campus in a specially designated residence hall, attending classes with undergraduates. Every admitted student receives tuition, housing, and meals. The Gatton Academy seeks to represent the full diversity of Kentucky, recruiting in every county of the state. Half of the students selected each year are female. Because a full scholarship is provided to every admitted student, the program is successful in including students from a variety of socioeconomic backgrounds.

Students at the Gatton Academy are encouraged to seek out opportunities to work with faculty conducting research in a variety of disciplines and to do so early, as soon as they are acclimated to their new learning environment. Original, mentored research is one of the major focus areas of the program. Facilitating student research opportunities with university faculty mentors starts as soon as new students arrive, via a research fair where faculty meet students and share opportunities for students to get involved within their labs and research groups (Roberts, 2013). Students also receive one-on-one advising help from other students to assess their interests, consider their options, and

Journal of the Scholarship of Teaching and Learning, Vol. 21, No. 1, April 2021. josotl.indiana.edu 
learn what will be expected in the process. Although participating in mentored research is optional, approximately $85 \%$ of students pursue this opportunity (695 of the 823 graduates to date). It is a foundational cultural value of the Gatton Academy to keep research optional so that a student's own curiosity guides the process. Although the Gatton Academy supports students throughout the research process, from finding a mentor to conducting original work to producing outcomes, engagement at every stage is student initiated (Roberts et al., 2016).

The Gatton Academy's key partnership is with faculty of Western Kentucky University, where the program is housed. The students are mentored directly by university faculty but frequently receive additional coaching, guidance, and training through the university's tiered mentoring approach from student mentors who are often more experienced undergraduates or older Gatton Academy students within the research group. For example, one of the authors had a multi-year sustained linkage of Gatton Academy research students, consisting of Gatton seniors recruiting juniors they deemed a good fit with the research group and project. Mentored projects can take place in any department or college at the university where a student receives mentorship but most often are in the natural and social sciences. Research involving collaboration between undergraduates and high school students is diverse and occurs in many academic departments. Recent examples included Gatton Academy students teaming up with advanced undergraduate researchers on behavioral science studies of substance abuse and family history (Wilgruber, Blevins, \& Teeters, 2020) and the impact of trait anxiety on study strategy choices (King, Redifer, \& Young, 2019). Mentoring roles in these projects were shared by faculty members and advanced undergraduate researchers. In materials chemistry, a Gatton Academy student learned from both her mentor and advanced undergraduates, using nanomaterials to develop new polymers for future technologies (Nguyen \& Hill, 2020). By the student's second year, the more advanced undergraduate students had graduated and she entered the peer mentoring role, as less-experienced students joined the group. Recently, Gatton Academy students with strong computational and coding abilities were invited to join a team of engineering undergraduates. The engineering undergraduates designed a working apparatus to examine fairness of worldwide dice games, and Gatton Academy students were brought on to become the computer scientists on the team, creating a neural network to read dice rolls and a database to record and analyze results (Campbell \& Dolan, 2019).

At any given time, a faculty member's research group may consist of graduate students, advanced undergraduate students, new undergraduate students, and high school students. This structure allows undergraduates to experience the value of serving as a mentor to high school juniors and seniors. The opportunity to co-mentor (alongside faculty) gives undergraduate researchers practice providing feedback and experience exercising leadership skills, which increases their research self-efficacy. Faculty, then, serve not only as research mentors but also as "mentoring mentors." Tiered mentoring provides undergraduates with insight into all aspects of the research process and better prepares them for careers requiring supervision of others. Since the Gatton Academy's inception in 2008, students have authored over 1,100 research presentations, with an average of over 100 presentations per year in the past decade. Among those graduating from the Gatton Academy from 2008 to 2014, 70\% went on to major in STEM disciplines.

At the institutional level, both student participation in research and the mentoring of students have been metrics in our university's recent strategic plans. The previous strategic plan sought to increase the number of student presentations at our university's annual research conference. The conference has been held since 1970 and has expanded from a strictly science-based conference to include all forms of original student research and creative activity. It is open to graduate students, undergraduate students, and Gatton Academy students. The previous strategic plan called for an increase in presentations at the conference by 50\%, from 215 total student presentations in 2011 to 325 student presentations in 2018 (Western Kentucky University, 2012). That goal was surpassed in

Journal of the Scholarship of Teaching and Learning, Vol. 21, No. 1, April 2021. josotl.indiana.edu 
2014 as the culture of student research and faculty mentorship took greater hold at the university. Our university's current strategic plan calls for mentorship of students to be considered in faculty hiring, annual review, the tenure and promotion process, merit pay allocations, and faculty workload decisions (Western Kentucky University, 2018), sustaining a shift to a faculty more involved in scholarly activity. The location of the Gatton Academy on our campus and the university's strategic emphasis on student research have contributed to our culture of involving students at all levels in all aspects of the research process. This structure makes a tiered-mentoring approach ideal on our campus, but many of the strategies employed at our regional comprehensive university are applicable in other postsecondary settings.

\section{Supporting Mentored Summer Research in University Settings}

Federal agencies and professional organizations offer funding to build mentorship programs and programs that involve high school students in faculty research. For example, the National Science Foundation (NSF) Research in Undergraduate Institutions (RUI) award has funded travel expenses for high school, undergraduate, and graduate students conducting field research as part of faculty research initiatives. A recent RUI award at our institution included Kentucky high school students and high school students from Barrow, Alaska, which facilitated cultural exchange in addition to multitiered mentorship. Another example is our university's Project SEED grant, awarded to a chemistry faculty member by the American Chemical Society. This large-scale program has provided thousands of summer chemistry research internships to high school students from economically disadvantaged backgrounds. Students spend 8 to 10 weeks under the mentorship of a faculty member, working on independent research projects. At the University of Kentucky, the National Institutes of Health awarded a grant to the Markey Cancer Center to study cancer among populations from Appalachian areas. One dimension of the program is an on-campus, residential summer program for high-school-aged Appalachian students to participate in mentored research with faculty who study oncology. At our institution, increased undergraduate research has resulted in faculty mentors receiving five NSF Research Experience for Undergraduate awards. Moreover, faculty mentors have actively sought external funding for undergraduate researchers. From 2014 to 2019, the Kentucky NSF Established Program to Stimulate Competitive Research (EPSCOR) provided seed funding each year for underrepresented undergraduate researchers in Kentucky to work with faculty mentors. Faculty mentors at all Kentucky private and public institutions were eligible to apply. Western Kentucky University faculty members received 28 of 37 EPSCOR Research Scholar Program awards for a total of $\$ 327,000$. Along with its beneficial impact on student experiences, tiered mentoring has increased faculty and institutional research outcomes.

In addition to summer programs that fall under the umbrella of federal initiatives, other institutions have arranged independent summer programs to involve students in mentored research. For example, at Vanderbilt University, the Research Experience for High School Students is a 6-week program that involves local students in an intensive, mentored project in the sciences. Cincinnati Children's Hospital hosts the High School Senior Summer Internship Program, which provides a halftime (20 hr per week) internship to students. Interns are paired with a clinical mentor, learn about careers in medicine and clinical research, and carry out independent, mentored research projects. Kansas's Bethel College offers a 1-week science research program that includes a peer-mentoring element where a faculty member and undergraduate research mentors lead a small team of high school students through a short-term, original research project. An evaluation of the Bethel College Summer Science Institute indicated that even a week-long research immersive experience motivated high school students to consider further STEM study (Krehbiel \& Piper, 2017). The High School Summer Research Program at the University of California, Los Angeles is an example of a collaboration

Journal of the Scholarship of Teaching and Learning, Vol. 21, No. 1, April 2021. josotl.indiana.edu 
between a high school and a university. They developed a strategic partnership to host a residential, 8 -week mentored research program for rising high school seniors. The program aims to involve high school students in original, mentored projects, develop students' science communication abilities, nurture their social growth, and help students identify options and pathways for their futures (Kittur, Shaw, \& Herrera, 2017). Thus, many pathways to tiered research mentorship involving high school students are possible, ranging from individual faculty recruitment at local high schools to federally funded structured programs.

\section{Conclusions}

The tiered-mentoring approach described here facilitates the involvement of high school students in postsecondary research. Additionally, it provides more advanced student researchers with the opportunity to gain leadership experience, by serving as peer mentors to high school student researchers. Tiered mentoring serves practical purposes by allowing faculty to delegate some managerial tasks to advanced students, facilitating efficiency and lab productivity. Many faculty researchers already assign leadership roles to advanced student researchers; establishing a more formal tiered approach can expand research opportunities to those outside the university community. High school students can make valuable contributions to university research groups. Undergraduate, graduate, and faculty researchers can, in turn, play an important role in the growth and aspirations of high school student researchers.

\section{References}

Almarode, J, Subotnik, R. F., \& Lee, G. M. (2016). Specialized STEM high schools. Gifted Child Today, 39(4), 181-182. https://doi.org/10.1177/1076217516662099

American Psychological Association. (2016). Conducting psychological research for science fairs: A teacher's guide and resource manual. https://www.apa.org/education/k12/science-fair-manual.pdf

American Psychological Association. (2020). Research mentors. https://www.apa.org/ed/precollege/topss/research-mentor

Atkinson, R. D., Hugo, J., Lundgren, D., Shapiro, M. J., \& Thomas, J. (2007). Addressing the STEM challenge by expanding specialty math and science high schools. The Information Technology and Innovation Foundation. https://itif.org/publications/2007/03/20/addressing-stemchallenge-expanding-specialty-math-and-science-high-schools

Berkes, E., \& Hogrebe, M. (2007, April). Undergraduate laboratory research, persistence in science, and the effect of selfeefficacy beliefs: A quantitative study. Paper presented at the American Educational Research Association, Chicago, IL.

Bhattacharyya, P., Chan, C. W. M., \& Waraczynski, M. (2018). How novice researchers see themselves grow. International Journal for the Scholarship of Teaching and Learning, 12(2), 1-7. https://doi.org/10.20429/ijsotl.2018.120203

Campbell, C.W., \& Dolan, W.P. (2019, March). Dice mythbusters. Paper presented at the Annual Student Research Conference at Western Kentucky University, Bowling Green, KY. https://digitalcommons.wku.edu/sel_pres/48

Committee on Prospering in the Global Economy of the 21st Century: An Agenda for American Science and Technology; National Academy of Sciences; National Academy of Engineering; \& Institute of Medicine. (2007). Rising above the gathering storm: Energizing and employing America for a brighter economic future. Washington, DC: The National Academic Press.

Journal of the Scholarship of Teaching and Learning, Vol. 21, No. 1, April 2021. josotl.indiana.edu 
Duran, D. (2017). Learning-by-teaching. Evidence and implications as a pedagogical mechanism. Innovations in Education and Teaching International, 54(5), 476-484. https://doi.org/10.1080/14703297.2016.1156011

Evans, D. J. R., \& Cuffe, T. (2009). Near-peer teaching in anatomy: An approach for deeper learning. Anatomical Sciences Education, 2(5), 227-233. https://doi.org/10.1002/ase.110 Every Student Succeeds Act, 114 U.S.C. S. 1177, \$S4102-4107 (2015).

Fechheimer, M., Webber, K., \& Kleiber, P. B. (2011). How well do undergraduate research programs promote engagement and success of students? Life Sciences Education, 10, 156163. https://doi.org/10.1187/cbe.10-10-0130

Galbraith, J., \& Winterbottom, M. (2011). Peer-tutoring: What's in it for the tutor? Educational Studies, 37(3), 321-332. https:/ / doi.org/10.1080/03055698.2010.506330

Gatton Academy. (2018). Climbing to greater heights. Retrieved from https://www.wku.edu/strategicplan/documents/climbingtogreaterheights.pdf

Hayes, S. M. (2018). Engaging early-career students in research using a tiered mentoring model. In

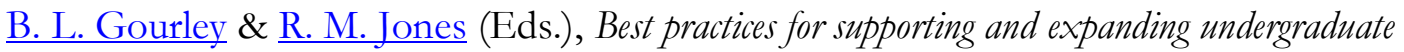
research in chemistry (ACS Symposium Series, Vol. 1275, pp. 273-289). American Chemical Society. https://doi.org/10.1021/bk-2018-1275.ch016

Jaswal, F., \& Jaswal, T. M. (2008). Tiered mentoring to leverage student body expertise. New Directions for Community Colleges, 2008(144), 55-61.

Jones, B. M. (2009). Profiles of state-supported residential math and science schools. Journal of Advanced Academics, 20(3), 472-501. https://doi.org/10.1177/1932202X0902000305

King, H.M., Redifer, J.L., \& Young, R. (2019, May). Trait anxiety and procrastination predict surface study strategy use. Poster presented at the 31st Annual Convention of the Association for Psychological Science, Washington, DC.

Kittur, H., Shaw, L., \& Herrera, W. (2017). A new model for a multi-disciplinary engineering summer research program for high school seniors: Program overview, effectiveness, and outcomes. Journal of STEM Education, 18(4), 25-30.

Kiyama, J. M., \& Luca, S. G. (2014). Structure opportunities: Exploring the social and academic benefits for peer mentors in retention programs. Journal of College Student Retention: Research, Theory \& Practice, 15(4), 489-514. https://doi.org/10.2190/CS.15.4.b

Kman, N. E., Bernard, A. W., Khandelwal, S., Nagel, R. W., \& Martin, D. R. (2013). A tiered mentorship program improves number of students with an identified mentor. Teaching and Learning in Medicine, 25(4), 319-325. https://doi.org/10.1080/10401334.2013.827976

Krehbiel, D., \& Piper, J. K. (2017). Recruiting STEM students with brief summer research experiences: An opportunity for colleges and their alumni. Journal of STEM Education, 18(4), $17-24$.

Kuh, G. D. (2008). High-impact educational practices: What they are, who has access to them, and why they matter. Association of American Colleges and Universities. https://www.aacu.org/publications-research/publications/high-impact-educationalpractices-what-they-are-who-has-access- 0

Lave, J. (1996). Teaching, as learning, in practice. Mind, Culture, and Activity, 3(3), 149-164. https://doi.org/10.1207/s15327884mca0303_2

Lopatto, D. (2010). Undergraduate research as a high-impact student experience. Association of American Colleges and Universities, 12(2). https://www.aacu.org/publicationsresearch/periodicals/undergraduate-research-high-impact-student-experience 
MacPhee, D., Farro, S., \& Canetto, S. S. (2013). Academic self-efficacy and performance of underrepresented STEM majors: Gender, ethnic, and social class patterns. Analyses of Social Issues and Public Policy, 13(1), 347-369. https://doi.org/10.1111/asap.12033

Morrison-Beedy, D., Aronowitz, T., Dyne, J., \& Mkandawire, L. (2001). Mentoring students and junior faculty in faculty research: A win-win scenario. Journal of Professional Nursing, 17(6), 291-296.

Murray, D. H., Obare, S., \& Hageman, J. (2016). Early research: A strategy for inclusion and student success. In D. H. Murray, S. Obare, \& J. Hageman (Eds.), The power and promise of early research (pp. 1-32). Washington, DC: American Chemical Society. https://doi.org/10.1021/bk-20161231.ch001

Nagda, B. A., Gregerman, S. R., Lerner, J. S., Von Hippel, W., \& Jonides, J. (1998). Undergraduate student-faculty research partnerships affect student retention. The Review of Higher Education, 22(1), 55-72. https://doi.org/10.1353/rhe.1998.0016

National Survey of Student Engagement. (2005). Student engagement: Exploring different dimensions of student engagement. Bloomington, IN: Indiana University Center for Postsecondary Research.

Nguyen, N., \& Hill, L. (2020, March). Synthesis of a novel degradable polymer susceptible to oxidation. Poster presented at Posters-at-the-Capitol, Frankfort, KY.

Puslednik, L., \& Brennan, P. C. (2020). An Australian-based authentic science research programme transforms the 21st century learning of rural high school students. Australian Journal of Education, 64(2), 98-112. https://doi.org/10.1177/0004944120919890

Roberts, J. L. (2013). The Gatton Academy: A case study of a state residential high school with a focus on mathematics and science. Gifted Child Today, 36(3), 193-200. https://doi.org/10.1177/1076217513486649

Roberts, J. L., Breedlove, L., \& Strode, D. (2016). Experiential learning at the Gatton Academy of Mathematics and Science in Kentucky. Gifted Child Today, 39(4), 228-235. https://doi.org/10.1177/1076217516662097

Western Kentucky University. (2012). Challenging the spirit: Action plan 2012-2013 to 2017-2018. Retrieved from https://www.wku.edu/convocation/documents/challenging the spirit action plan 12 18.p df

Wheeler High School. (2020). The Senior Internship \& Research Experience. Retrieved from https://www.wheelermagnet.com/senior_research.html

Willgruber, A., Blevins, A., \& Teeters, J. B. (2020, April). Family history of illicit drug use moderates the relations between PTSD and cannabis use disorder. Poster presented at the Collaborative Perspectives on Addiction 8th Annual Conference (American Psychological Association Division 50). Yale University. (2020). 4-Tiered Mentoring Program. Retrieved from https://gsas.yale.edu/diversity/current-students/4-tiered-mentoring-program 